\title{
Hypothermia-induced amnesia for newly acquired and old reactivated memories: Commonalities and distinctions
}

\author{
CHARLES F. MACTUTUS, JACQUELYN M. FEREK, CATHERINE A. GEORGE, \\ and DAVID C. RICCIO \\ Kent State University, Kent, Ohio
}

\begin{abstract}
A series of six experiments compared the characteristics of hypothermia-induced amnesia for newly acquired and old reactivated memories. Old memory, when reactivated by cue exposure, was disrupted by mild or deep hypothermia treatment, while new memory was impaired only by deep cooling. Mild hypothermia had no disruptive influence on either new or old memories. Old, but not new, learning showed recovery from amnesia in a test-retest procedure. The onset of amnesia was more rapid for an old reactivated memory than for a newly acquired memory. The susceptibility of memory to disruption decreased over time following original learning or cue reactivation, although this decrease was, if anything, more rapid following the cuing procedure. Recovery from amnesia could be induced by a recooling reminder treatment and was similar for both new and old memories. It was suggested that activity of, or access to, memory rather than age per se determines susceptibility to disruption. The process of memory reactivation appears somewhat more sensitive, rapid, and brief than the process(es) of memory formation. However, that the underlying old memory remains stable over time was supported by the strong retention when specific implicit or explicit reactivation cues were available.
\end{abstract}

The temporal organization has long been held as an important dimension in the study of the diseases of memory. Since the late 19th century, when Ribot (1883) formulated his "law of regression," old memories have been viewed as more stable and less susceptible to disruption than recently acquired learning. However, since this rule was based on anecdotal and observational reports of human amnesia and senility, it is not surprising that the clinical literature suggests little agreement on the validity of Ribot's principle (Frankel, 1977; Robertson \& Inglis, 1977; Rozin, 1976; Russell, 1971; Schacter \& Crovitz, 1977; Whitty \& Zangwill, 1966, 1977). In contrast with the disagreement in clinical evidence, many early reports of experimentally induced amnesia in animals

This research is based in part on a dissertation submitted by the first author in partial fulfillment of the requirements of the $\mathrm{PhD}$ at Kent State University. These studies were supported by NIMH Grant MH30223 to, and conducted in the laboratories of, David C. Riccio. We acknowledge the constructive criticisms of G. Killian, B. Foote, B. H. Newberry, T. J. Teyler, and F. R. Treichler in early versions of the manuscript. Thanks are also due J. S. Young for critical reading of later drafts. Jacquelyn M. Ferek is now with the Department of Psychology at the University of Nevada at Reno. Reprint requests may be addressed to either C. F. Mactutus, who is now at the National Institutes of Health, National Institute of Environmental Health Sciences, Laboratory of Behavioral and Neurological Toxicology, P.O. Box 12233, Research Triangle Park, North Carolina 27709, or to D. C. Riccio, Department of Psychology, Kent State University, Kent, Ohio $\mathbf{4 4 2 4 2 .}$
(Duncan, 1949; Glickman, 1961; McGaugh, 1966) were consonant with Ribot's view. The time-dependent increase in resistance of memory to disruption by traumatic events delivered to the central nervous system is one basic tenet of the "traditional" consolidation theory of memory (Hebb, 1949).

Within a little more than the last decade, a number of studies have revealed several major shortcomings of the consolidation position and have also suggested that the degree of activation of a memory rather than the age of the information may determine its vulnerability to insult (cf. Lewis, 1979). Observations that severely strained a traditional consolidation interpretation of memory processing include a delay in the onset of experimentally induced retrograde amnesia (Geller \& Jarvik, 1968; Mactutus \& Riccio, 1978), the attenuation of amnesia by pretraining exposure to the training apparatus (Lewis, Miller, \& Misanin, 1968, 1969), and the reversal of amnesia by reminder treatments (Hinderliter, Webster, \& Riccio, 1975; Koppenaal, Jagoda, \& Cruce, 1967; Miller \& Springer, 1972; Quartermain, McEwen, \& Azmitia, 1970; Thompson \& Neely, 1970). Furthermore, detaining animals in the apparatus immediately after training prolonged the interval for effective amnesic treatment (Davis \& Agranoff, 1966; Robustelli, Geller, \& Jarvik, 1968). But perhaps most importantly, evidence was revealed that old memories brought back to an "active" state by a reminder treatment were again susceptible to disruption by an 
amnesic agent (Misanin, Miller, \& Lewis, 1968; Schneider \& Sherman, 1968). This latter finding most directly supports the position that the age of the memory is not the primary determinant of its susceptibility to disruption, since the amnesia is induced at a time well beyond the consolidation or fixation period (Lewis, 1969, 1976, 1979).

Caution is warranted in evaluating the evidence that the activity of a memory, not its age, is the primary determinant of its vulnerability. While a number of independent laboratories have replicated the finding of amnesia for old reactivated memories (Davis \& Hirtzel, 1970; DeVietti \& Holliday, 1972; Gerson \& Henderson, 1978; Misanin et al., 1968; Robbins \& Meyer, 1970; Schneider \& Sherman, 1968), many negative findings have also been obtained (Banker, Hunt, \& Pagano, 1969; Dawson \& McGaugh, 1969; Gold \& King, 1972; Jamieson \& Albert, 1970; Weaver \& Geoffrey, 1969). The one clinical adaptation of this paradigm (Squire, Slater, \& Chance, 1976) also reported no detectable amnesia for an old reactivated memory following electroconvulsive therapy (ECT), although amnesia is a common sequela for learning shortly prior to ECT (Cronholm \& Lagergren, 1959; Zubin \& Barrera, 1941). The reasons for these discrepancies are not at all clear. While the failures may be taken as evidence for a qualitative change of memory over time, the positive replications support the more parsimonious contention that new and old memories share similar characteristics.

A quite different approach by Gordon and his colleagues employing nonamnesic treatments has provided additional evidence that the modification of a memory depends upon its state of activity. For example, both new and old memories in an active state may be enhanced by analeptic drugs such as strychnine sulfate (Gordon, 1977a; Gordon \& Spear, 1973b). Moreover, recent evidence suggests that newly acquired and reactivated memories have comparable interfering effects on later retention (Gordon, 1977b; Gordon \& Feldman, 1978; Gordon, Frankel, \& Hamberg, 1979; Gordon \& Spear, 1973a). These reports of apparent similarities suggest that once a memory is reactivated it returns to the same status that it had shortly after learning (Lewis, 1969, 1976, 1979).

While these reported similarities are impressive, a systematic examination of the comparability of the characteristics of new and old memories in an active state has yet to be reported. Accordingly, the present series of studies was designed to provide a direct comparison of the susceptibility to disruption of newly acquired and old reactivated memories. The study of the characteristics of an old "active" memory in an amnesic paradigm would also provide an experimental assessment of the validity of Ribot's law. Moreover, the use of hypothermia as an amnesic agent extends the generality of an effect almost exclusively reported with ECS as the amnesic agent (but see Davis \& Klinger, 1969; Judge, Haraczkiewicz, \& Quartermain, Note 1). The individual experiments addressed the issues of replicability and generality, spontaneous recovery, specificity, onset, temporal gradient of disruption, and induced recovery, with respect to amnesia for old and new memories.

\section{GENERAL METHOD}

Since similar procedures and the same apparatus were employed in all of the following experiments, the details of those are presented only once. Specific treatments that represent departures from, or additions to, the general method are described within individual experiments.

\section{Subjects}

All subjects were adult male albino rats purchased from the Holtzman Company. The animals were housed in the colony for at least 1 week upon receipt from the supplier prior to the start of any experiment. The colony was maintained on a 16-h-light/ 8 -h-dark cycle, with an ambient temperature of $20^{\circ}-22^{\circ} \mathrm{C}$. Throughout each study, food and water were provided ad lib in the animals' home cages.

\section{Apparatus}

The main apparatus was a passive-avoidance (PA) chamber $(45.5 \times 17.5 \times 23.5 \mathrm{~cm})$ constructed of Perspex and aluminum. The chamber was divided into two equal-sized compartments by a partition with a $6.5 \times 9.0 \mathrm{~cm}$ opening that could be blocked by lowering a door. While one compartment had white walls and a clear Perspex lid, the second compartment had both black walls and a black lid. The flooring was identical in both compartments, .20 -cm grids spaced $1.0 \mathrm{~cm}$ apart, but only the grids on the black side were connected to a scrambled shock source. A $1-\sec 150-\mathrm{V}$ shock from a fixed-impedance source (Masterson \& Campbell, 1972) was delivered via a Foringer Model SC-901 scrambler. The experimental room for the PA apparatus was illuminated by a $15-W$ incandescent bulb suspended $30 \mathrm{~cm}$ above the center of the white compartment. Standard electromechanical equipment was employed to monitor each animal's cross-through latency to the nearest $.1 \mathrm{sec}$.

Both mild and deep hypothermia were produced, using a Model 1095 Forma Temp Jr. water bath and circulator, maintained at $4.0^{\circ} \pm 1^{\circ} \mathrm{C}$. Mild hyperthermia was produced using an additional Model 1095 Forma Temp Jr. water bath and circulator, maintained at $45.0^{\circ} \pm 1^{\circ} \mathrm{C}$. Wire cloth tubes served to restrain subjects during the immersion periods. A Yellow-Springs TeleThermometer, Model 43 TD, was employed along with a rectal probe to record body temperature.

\section{Procedure}

Pretraining. One day prior to training, all animals were weighed, ear punched for purposes of identification, individually caged, and handled for a 5-min period.

Training. On the training day, each rat was taken in a transport cage (a standard stainless steel cage) to the experimental room, where it received a single training trial in the black-white PA chamber. On the trial, the rat was placed in the white compartment facing away from the door separating the two chambers. Ten seconds later, the door was raised and the latency for the animal to cross through into the black chamber (all four feet) was recorded to the nearest $.1 \mathrm{sec}$. Contingent upon the cross-through response, each animal received an inescapable 1-sec 150-V scrambled footshock and was subsequently removed from the apparatus and returned to the colony.

Cue exposure. Reexposure to the PA box used in training was employed to produce reactivation of the target memory. Specifically, this reactivation treatment was administered $24 \mathrm{~h}$ after original training. Animals were moved to the experimental room via 
a stainless steel transport cage, placed in the darkened compartment of the PA box for $30 \mathrm{sec}$ without footshock, and then returned to the colony. Similar procedures have met with considerable success for the reactivation of a memory in other paradigms (e.g., Spear, 1973).

Hypothermia. The specific details of the hypothermia immersion treatment were as previously employed (Hinderliter et al., 1975). Briefly, the animals were restrained in wire cloth tubes within $30 \mathrm{sec}$ of footshock termination or cue exposure and immersed to neck level in $4^{\circ} \mathrm{C}$ water. For the deep hypothermia treatment, if, after $10 \mathrm{~min}$, body temperature was not $21^{\circ} \mathrm{C}$ or below, the animals were reimmersed for 30 -sec periods until this criterion was met. For the mild hypothermia treatment, the immersion period lasted only $3 \mathrm{~min}$, yielding a reduction in body temperature to approximately $30^{\circ} \mathrm{C}$. Body temperature was assessed by insertion of a lubricated rectal probe $3.2 \mathrm{~cm}$ into the rat's anus. Upon reaching the immersion criterion, the animals were removed from the water bath and wire cloth tubes, wiped with paper towels to remove excess moisture, and returned to their home cages.

Testing. The traditional cross-through response latency on a PA test trial served to assess the retention of the original target memory (900-sec ceiling). The test trial was conducted identically to the training trial except that no footshock was administered. To obtain a second, more conservative measure of retention, all animals remained in the PA box for a full 15-min session, and their preference for the white (safe) side was also monitored (total time on white, TTW). Immediately after testing, the rectal temperature of each animal was also recorded.

Statistical analysis. Passive-avoidance training scores and posttest body temperatures were analyzed by parametric statistics. Because potential interaction terms were of great interest for the test data, and since parametric and nonparametric (Siegel, 1956) analyses led to the same interpretation, only the parametric statistics are reported. Specifically, analysis of variance (ANOVA) and, when appropriate, subsequent Newman-Keuls statistics were computed (Winer, 1971).

\section{EXPERIMENT 1}

Using deep hypothermia $\left(21^{\circ} \mathrm{C}\right)$ as the amnesic agent (Mactutus, Riccio, \& Ferek, 1979, Experiment 1), an initial investigation in our laboratory replicated earlier findings of amnesia for an old reactivated memory. Surprisingly, old memory was also disrupted by a cue-exposure/mild-hypothermia treatment $\left(30^{\circ} \mathrm{C}\right)$ originally intended to control for any systemic effect of stress. This unexpected disruption of memory was puzzling in light of a number of reports on the lack of effect of immediate posttrial stress on subsequent retention (Grosser \& Percy, 1971; Kane \& Jarvik, 1970; Marlin, Greco, \& Miller, 1978; but also see Mondaduri, Waser, \& Huston, 1977) and the previous evidence that mild hypothermia did not disrupt newly acquired learning (Riccio, Hodges, \& Randall, 1968). Therefore, it seemed advisable to attempt to replicate the amnesic effect of mild cooling on reactivated memory.

An additional concern, generated by preliminary data, was to evaluate the generality of the stressor events that might disrupt an old reactivated memory. Since hyperthermia can have amnesic effects on retention (Jacobs \& Sorenson, 1969; Kane \& Jarvik, 1970; Mactutus, Ferek, \& Riccio, 1980;
Misanin, Vonheyn, Bartelt, Boulden, \& Hinderliter, 1979), this agent was included in the design.

Thus, Experiment 1 was designed to compare the susceptibility to disruption of newly acquired and old reactivated memories by treatment with mild or deep hypothermia, or mild hyperthermia, immediately after training or memory reactivation.

\section{Method}

Seventy-eight rats (260-395 g) were used in this experiment. All animals received PA training and were then assigned randomly to one of eight treatment conditions. The vulnerability of new learning was evaluated with two groups of rats $(n s=11)$ that received either mild or deep hypothermia treatment within $30 \mathrm{sec}$ of footshock termination. The susceptibility of old memories to disruption was assessed by two groups of animals $(\mathrm{ns}=11)$ administered either mild or deep hypothermia, but only after a 24-h delay. Both of these latter groups received the brief 30 -sec fear cue exposure prior to their cold water immersion to produce reactivation of the target memory.

Because it was possible, although unlikely, that experience with cold water stress might produce rapid cross-through responding, two additional groups $(n s=6)$ received either mild or deep hypothermia $24 \mathrm{~h}$ after PA training, but without a prior reactivation treatment. Spear (1978) has suggested that any of a number of attributes that constitute a memory (Underwood, 1969) may serve as potential reactivators. To reduce the possibility that handling cues might inadvertently reactivate the target memory, these control rats were carried in a gloved hand when moved for the cooling treatment rather than in the transport cage that had been used to bring them to the training apparatus.

The generality of the disruption of an old reactivated memory by mild stress was directly addressed by two additional groups of rats $(\mathrm{ns}=11)$. One group received PA training followed immediately by a hyperthermia treatment; the second group received PA training followed $24 \mathrm{~h}$ later by a combined 30 -sec fear cue exposure/hyperthermia treatment. The hyperthermia procedure was similar to the mild hypothermia immersion (i.e., 3-min duration), except that the water bath temperature was $45^{\circ} \mathrm{C}$.

The interval between immersion treatment and the retention test was a constant $24 \mathrm{~h}$ for all groups. Since PA retention is typically very strong with adult rats (Ader, Weijnen, \& Moleman, 1972; Schulenberg, Riccio, \& Stikes, 1971), little, if any, forgetting based on the $24-h$ difference in retention interval was expected to confound the results. Nevertheless, the control groups that did not receive any prior reactivation treatment also permitted assessment of the amount of forgetting by the old reactivated memory groups attributable to their retention interval.

\section{Results and Discussion}

As may be seen in Table 1, prior to the shock punishment all eight groups performed similarly on the cross-through response $[F(7,70)=1.05, p<.400)$.

The mean test latencies $( \pm \mathrm{SEM})$ are presented in Figure 1. A $2 \times 3$ ANOVA on the test cross-through latency data of the six experimental groups indicated reliable effects of the age of the memory $[F(1,60)=$ $8.48, \mathrm{p}<.005]$, type of immersion treatment $[\mathrm{F}(2,60)$ $=73.54, \mathrm{p}<.001]$, and memory age $\times$ immersion treatment interaction $[\mathrm{F}(2,60)=24.55, \mathrm{p}<.001]$. Direct comparisons of the susceptibility to disruption of newly acquired and old reactivated memories indicated comparably short test latencies for both deep cooled groups regardless of the age of the memory, but the consequences of mild cooling on memory disruption 
Table 1

Mean Training Latency (in Seconds) and Posttest Rectal Temperature (in Degrees Centigrade) for all Treatment Groups in Experiment 1

\begin{tabular}{|c|c|c|c|c|}
\hline \multirow[b]{2}{*}{ Immersion Treatment } & \multicolumn{2}{|c|}{$\begin{array}{l}\text { Cross-Through } \\
\text { Training } \\
\text { Latency }\end{array}$} & \multicolumn{2}{|c|}{$\begin{array}{c}\text { Posttest } \\
\text { Rectal } \\
\text { Temperature }\end{array}$} \\
\hline & Mean & SEM & Mean & SEM \\
\hline & \multicolumn{4}{|c|}{ Newly Acquired Memory } \\
\hline Deep Hypothermia & 8.1 & 2.26 & 36.5 & .24 \\
\hline Mild Hypothermia & 7.3 & 2.33 & 36.4 & .27 \\
\hline \multirow[t]{2}{*}{ Mild Hyperthermia } & 8.6 & 2.70 & 36.8 & .37 \\
\hline & \multicolumn{4}{|c|}{ Old Cue Reactivated Memory } \\
\hline Deep Hypothermia & 5.7 & 2.63 & 36.6 & .16 \\
\hline Mild Hypothermia & 10.0 & 2.31 & 36.5 & .21 \\
\hline \multirow[t]{2}{*}{ Mild Hyperthermia } & 5.5 & 1.04 & 36.3 & .34 \\
\hline & \multicolumn{4}{|c|}{ Old Memory-No Reactivation } \\
\hline Deep Hypothermia & 14.8 & 6.18 & 36.9 & .17 \\
\hline Mild Hypothermia & 5.8 & 1.80 & 37.2 & .35 \\
\hline
\end{tabular}

depended upon the age of the memory. That is, the mild cooling treatment disrupted the old reactivated memory but had little behaviorally detectable effect on a recently acquired memory $(p<.01)$. While this disruption of old reactivated memory by mild cooling was not statistically different from that provided by deep cooling, mild cooling was ineffective relative to deep cooling in disrupting newly acquired memory $(p<.01)$. New learning was also not disrupted relative to deep hypothermia by the mild hyperthermia immersion $(p<.01)$. Similarly, old reactivated memory was not affected by mild hyperthermia when compared with deep cooling or even with mild cooling (ps $<.01$ ).

As Figure 1 also illustrates, and a $2 \times 3$ ANOVA for the six experimental groups confirmed, the conservative total time on white (safe side) measure indicated significant effects of the type of immersion treatment $[F(2,60)=14.47, p<.001]$ and of the memory age $\times$ immersion treatment interaction $[F(2,60)=13.92, p<.001]$. Although absolute levels of retention were higher with the TTW index, subsequent analyses revealed a pattern of results similar to those observed on the latency measure. The only difference detected by the TTW measure not observed in the latency data was that although both new and old memories were disrupted by deep hypothermia (ps $<.01$ and .05 , respectively), the new memory was more severely disrupted $(p<.01)$.

Additional evidence regarding the magnitude of the memory deficit for each of the three groups that experienced "memory failure" was noted in a $6 \times 2$ mixed-design ANOVA comparing the training and test latencies for the six experimental groups. Analysis of the group $\times$ session interaction $[F(5,60)=$ $41.85, \mathrm{p}<.001$ ] found no statistical evidence for residual memory in the groups that displayed amnesia. In contrast, all groups that demonstrated retention on the previous analyses achieved test scores significantly greater than their training latencies (ps $<.01$ ).

The remote possibility that the hypothermia treatments that produced the memory deficits acted retroactively on a 24 -h-old memory was ruled out by the high retention level of the cold-water-stress con-

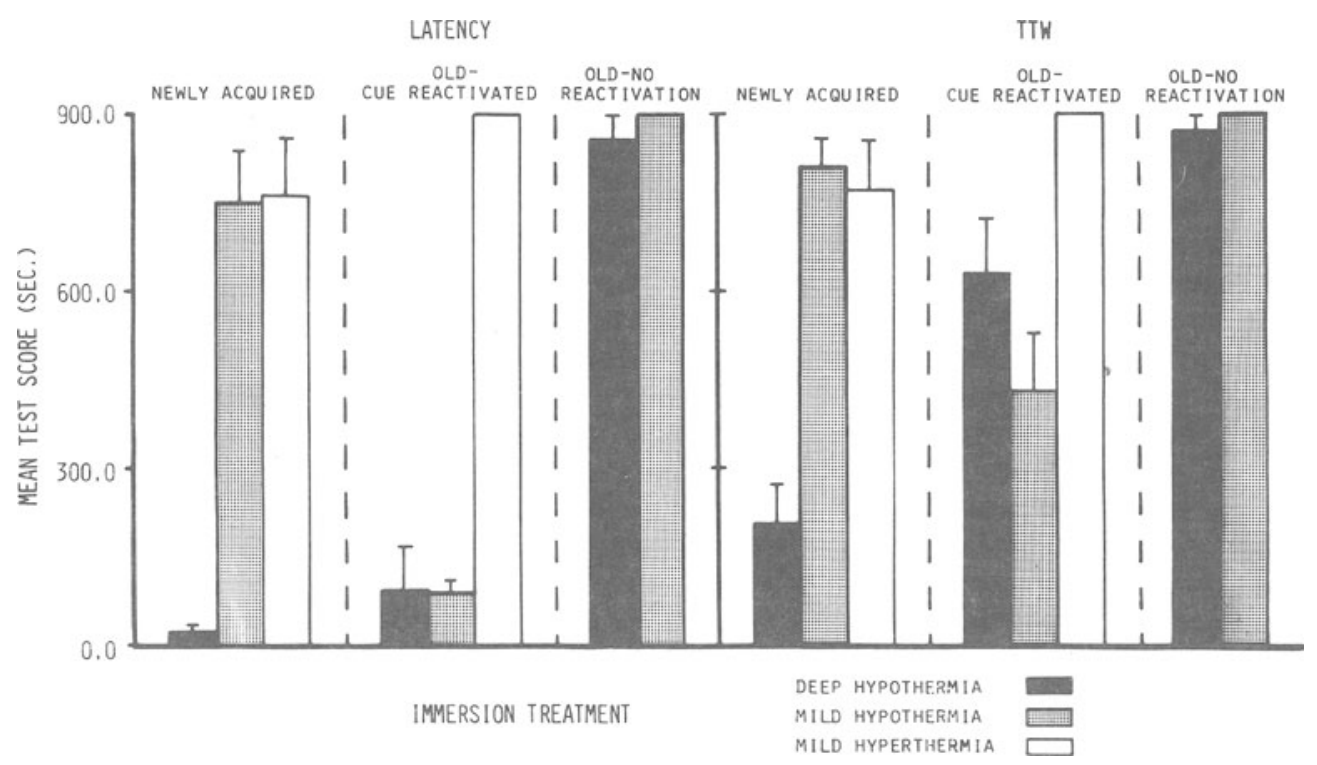

Figure 1. Mean test scores ( \pm SEM) on both latency and total time in white (safe) compartment (TTW) measures for rats administered either mild or deep hypothermia or mild hyperthermia immediately after acquisition of memory or after cued reactivation of a 24 -h-old memory. The retention scores of rats receiving mild or deep hypothermia $24 \mathrm{~h}$ after training but without prior reactivation treatment are also shown. 
trol animals. When either mild or severe cooling occurred $24 \mathrm{~h}$ after training, but without the reactivation treatment, 11 of 12 rats subsequently showed maximum avoidance $(900 \mathrm{sec})$.

The mean posttest rectal temperatures (Table 1) appeared normal for all eight groups. A one-way ANOVA performed on the temperature data indicated that, $24 \mathrm{~h}$ after cooling, no differences in body temperature were detectable $[F(7,70)<1.00]$; this result implies that long test latencies are not an artifact of differential motor debilitation. Evidence that the warming procedure did not increase activity was obtained from the test latency data, since heightened activity on a PA task would be expected to yield low, not high, cross-through scores.

In summary, across both retention measures, the observation of a memory deficit following a cue/ deep-hypothermia treatment substantiated previous reports (Misanin et al., 1968; Schneider \& Sherman, 1968) and replicated our initial experiment (Mactutus et al., 1979, Experiment 1). Furthermore, that retrograde amnesia may be induced for an old memory brought back to an active state confirms the generality of the effect originally suggested by Davis and Klinger (1969). The observation that a brief posttrial cooling episode was sufficient to produce severe amnesia for an old reactivated memory, but was insufficient to disrupt a newly acquired memory, also suggested a potential difference in the age-related characteristics of memory. However, the strong retention following mild hyperthermia treatment suggested a boundary condition on the nature of the stressor agents that may disrupt an old reactivated memory.

\section{EXPERIMENT 2}

Recovery from amnesia may provide another characteristic with which to assess the extent of memory disruption. Although memory recovery has been noted when amnesia has been induced immediately after training (Zinkin \& Miller, 1967), this effect generally is not observed (Lewis, 1969; McGaugh \& Herz, 1972; Miller \& Springer, 1973, 1974) and, in fact, appears limited to a repeated testing procedure (Herz \& Peeke, 1967, 1968; King \& Glasser, 1970). Others have argued that memory recovery occurs only after incomplete amnesia (Cherkin, 1972; Gold \& King, 1974). With respect to posttraining hypothermia-induced amnesia, Riccio and his colleagues (Hinderliter, Webster, \& Riccio, 1975; Riccio \& Stikes, 1969) have found no reliable evidence of memory recovery, even with a repeated testing procedure (Mactutus, 1977; Mactutus, McCutcheon, \& Riccio, 1980; Mactutus, Smith, \& Riccio, 1980).

One interesting possibility that has received some empirical support (DeVietti, Holliday, \& Larson, 1973; DeVietti \& Larson, 1971; DeVietti \& Zwanziger,
1975 ) is the occurrence of a more transient amnesia for old memory than for new learning. The converse finding, however, has also been reported (Bregman, Nicholas, \& Lewis, 1976).

The following experiment was designed to provide a systematic investigation of potential recovery from amnesia for both new and old memories in a testretest procedure.

\section{Method}

The three groups of rats that displayed amnesia on their initial test trial in Experiment 1 (i.e., the cue/mild-hypothermia, cue/ deep-hypothermia, and train/deep-hypothermia groups) were retested for evidence of memory recovery. Five subjects in each group were retested 3 days after original learning, and six subjects were retested 5 days after original learning. All 11 subjects were administered a third test 9 days after original learning.

\section{Results and Discussion}

The data from the subgroups retested either 3 or 5 days after original training were pooled to provide a larger sample for the "retest" session, as well as equal cell size. Thus, a $3 \times 3$ mixed-design ANOVA on the test latency data was performed for the three groups over their original (i.e., from Experiment 1), second, and third test scores. The mean test latency data are illustrated in Figure 2. Significant effects of group $[F(2,30)=7.17, p<.003]$, test session $[F(2,60)$ $=18.42, \mathrm{p}<.001]$, and group $\times$ test session interaction $[F(4,60)=4.73, p<.003]$ were observed. Subsequent analyses indicated that the latency scores of both the cue/mild-hypothermia and cue/deephypothermia groups increased reliably from the original to the retest session (ps $<.01$ ), but the train/ deep-hypothermia group showed no change. In addition, the retention scores of both cue/hypothermia groups did not differ from each other, and both were superior to the train/deep-hypothermia condition (ps $<.01)$. On the third test, the latency scores of both cue/hypothermia groups remained significantly higher than those of the train/deep-hypothermia group (ps $<.01$ ), as well as remaining higher than their respective original "amnesia" test scores (ps $<.05$ ).

Analyses of the TTW measure (Figure 2) detected reliable group $[F(2,30)=9.97, p<.001]$ and test session $[F(2,60)=3.03, p<.054]$ effects. Subsequent analyses indicated, similarly to the latency measure, that both cue/hypothermia groups had stronger retention than the train/deep-hypothermia groups on their retest scores (ps $<.01$ ). No group differences reached acceptable levels of significance on the third test. No changes in retention scores were noted across trials, with the exception of an increase in avoidance of the darkened compartment between original and retest sessions for the cue/mild-hypothermia group $(\mathrm{p}<.05)$.

A $2 \times 3$ ANOVA comparing original training and third-test latency scores for the three experimental 


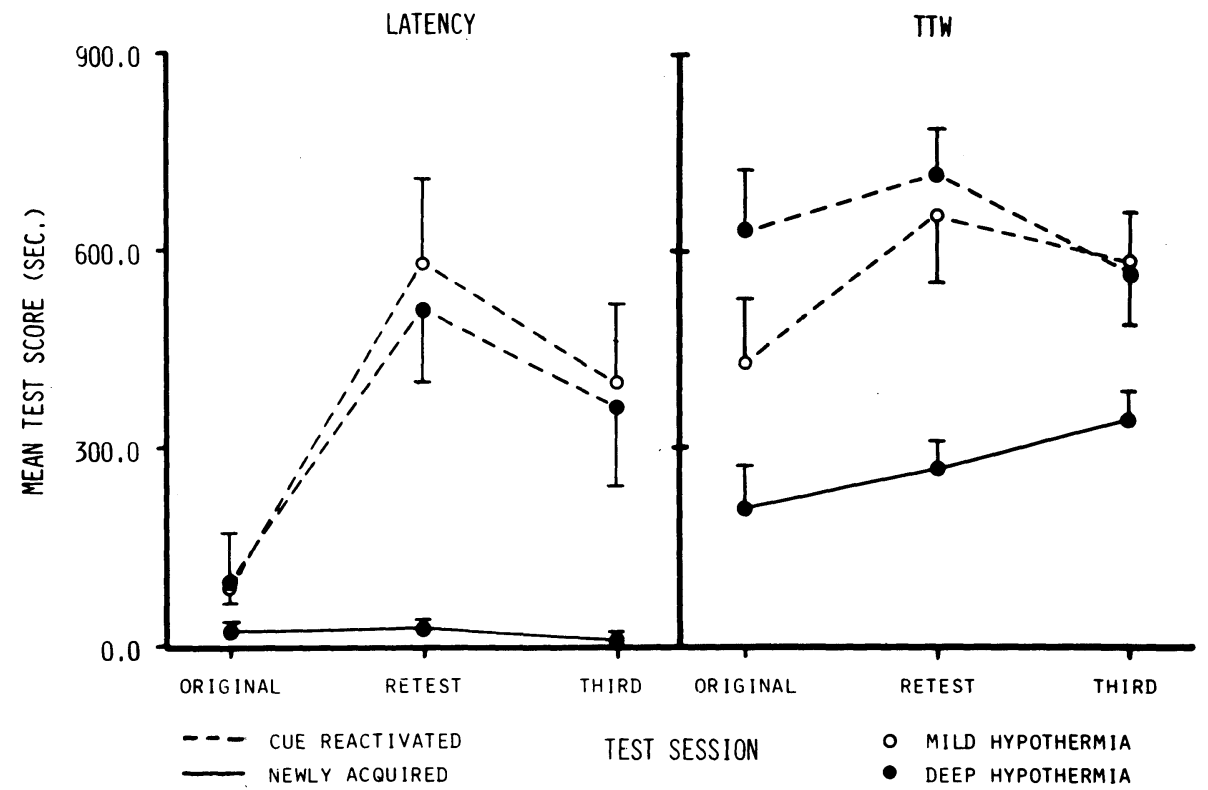

Figure 2. Mean test scores $( \pm$ SEM) on both latency and TTW measures for the rats of the new and old memory groups following deep hypothermia and for the old memory group following mild hypothermia as a function of their original, retest, and third test sessions.

groups found a significant treatment $\times$ session interaction $[F(2,30)=4.90, \mathrm{p}<.014]$. Subsequent analyses indicated the third test scores of the train/deephypothermia group approximated their original training latencies, while those of both cue/hypothermia groups were significantly greater than their respective training measures (ps $<.01)$.

Collectively, the data suggested that recovery occurred for old, but not new, memory following an amnesic treatment. While the test-retest procedure has the drawback that the initial session may provide an implicit reactivation episode (King \& Glasser, 1970; Spear, 1973), this confound was also applicable to the new learning group, which failed to show a change in retention scores across test trials.

\section{EXPERIMENT 3}

It is possible that the greater susceptibility to disruption of old reactivated memory over newly acquired memory found in Experiment 1 was an artifact of the combined cue-exposure/mild-cooling episode. According to this position, memory disruption should not be observed following mild cooling alone, but only when the effects of mild cooling summate with the effects of brief cue exposure, a nominal extinction trial.

The purpose of employing the brief cue exposure was to activate a dormant memory, a procedure obviously unnecessary with new learning. Moreover, there is reason to believe that, while exposure to a conditioned stimulus alone constitutes an extinction trial, a brief conditioned stimulus exposure does not reduce the strength of a previously acquired memory (Mactutus et al., 1979, Experiment 1) and may, quite paradoxically, enhance retention (Rohrbaugh \& Riccio, 1970; Gordon, Note 2). Nevertheless, as the temporal spacing of a cue-exposure treatment may alter its effect on memory (Robustelli, Geller, \& Jarvik, 1972), the following experiment was designed to assess the effect of a combined cue/mild-hypothermia treatment relative to a retention control group that received only PA training. We felt that this would permit detection of even a slightly disruptive influence of the cue/mild-cooling episode on a newly acquired memory.

\section{Method}

Twenty-two rats $(260-390 \mathrm{~g})$ received one-trial PA training. A randomly selected group of 10 rats received no further treatment and were returned to their home cages. The remaining 12 subjects were each detained in the black compartment for $30 \mathrm{sec}$ following footshock termination and then received a brief 3-min cooling immersion treatment. The retention of all rats was assessed $24 \mathrm{~h}$ after training.

\section{Results and Discussion}

The mean $( \pm$ SEM) cross-through latencies prior to shock punishment were $17.6 \pm 5.26 \mathrm{sec}$ for the retention control animals and $26.6 \pm 5.33 \mathrm{sec}$ for the new learning experimental group. Although these initial latencies were slightly longer than typically obtained, no significant difference between the groups was noted $[\mathrm{F}(1,20)=1.39, \mathrm{p}<.251]$.

Figure 3 presents the retention test scores as a function of the experimental treatments. As illustrated, neither a reliable difference in cross-through 


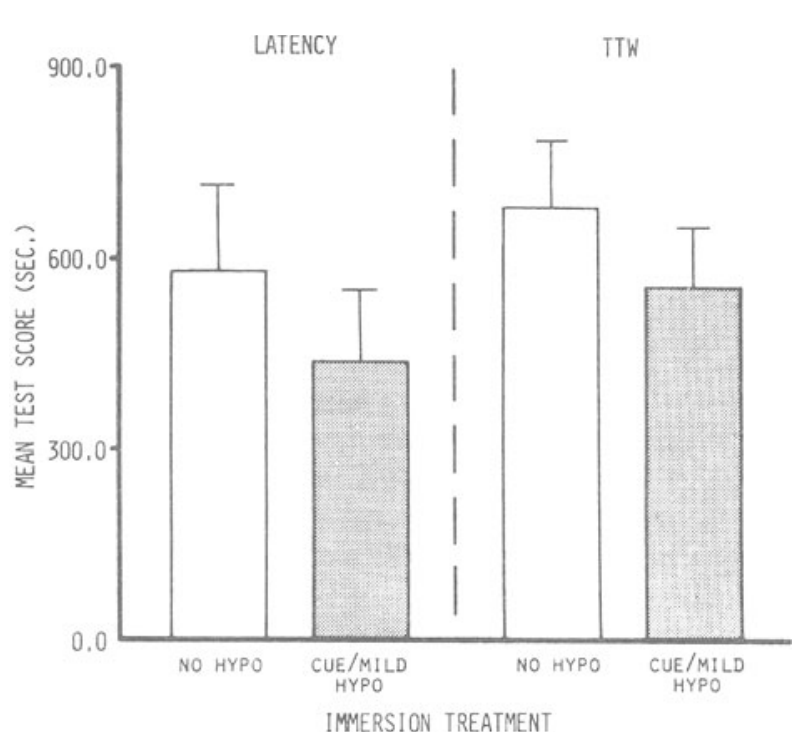

Figure 3. Mean test scores ( \pm SEM) on both latency and TTW measures for the control rats that received no hypothermia treatment and for the experimental rats that received a cue-exposure/ mild-hypothermia treatment immediately after PA training.

latency $[\mathrm{F}(1,20)<1.00]$ nor in TTW $[\mathrm{F}(1,20)<1.00]$ scores was detected. Subsequent analyses of a significant session effect $[F(1,20)=30.43, p<.001]$ from a $2 \times 2$ mixed-design ANOVA suggested substantial retention relative to the respective training latencies for both the retention control and new-learning/cueexposed/mild-hypothermia groups (ps $<.01)$. Mean $( \pm \mathrm{SEM})$ posttest rectal temperatures of the experimental group $\left(36.9^{\circ} \pm .19^{\circ} \mathrm{C}\right)$ were similar to those of the control group $\left(36.7^{\circ} \pm .23^{\circ} \mathrm{C}\right)$ that had not received an immersion treatment $[\mathrm{F}(1,20)<1.00]$.

Thus, in what would seem to be a rather sensitive paradigm, no disruptive effect on a newly formed memory was noted when a cue-exposure/mildhypothermia treatment followed immediately after the training footshock. Although no data were obtained in this experiment to show that the same cueexposure/mild-hypothermia treatment would have produced disruption of an old memory, the retention scores of both groups in the present study were comparable to those of the retention control and cueonly control animals in an earlier study, in which the combined cue/immersion treatments disrupted old memory (Mactutus et al., 1979, Experiment 1). Moreover, animals from the same shipment as employed here were used in the following experiments, in which the combined cue/immersion procedure produced substantial disruption of an old memory.

\section{EXPERIMENT 4}

An interesting and reliable finding in retrograde amnesia experiments is the delayed onset of memory loss. For example, when hypothermia is administered immediately after training, the amnesia does not occur until several hours later (Hinderliter et al., 1975; Mactutus \& Riccio, 1978). Similar functions have been reported with electroconvulsive shock delivered immediately after training, although the estimated delay in development of amnesia varies from minutes (Miller \& Springer, 1973) to several hours (Geller \& Jarvik, 1968). Little is known, however, of the onset of amnesia for an old cuereactivated memory. In an early report (Davis \& Klinger, 1969), it was suggested that potassium chloride administered to goldfish produced amnesia two to three times more slowly when given following reexposure to the intertrial environment used in training than when delivered immediately after training.

The present study compared the onset of hypothermia-induced amnesia for newly acquired and old cue-reactivated memory. A short 4-h postimmersion interval was chosen, since strong retention should be observed for the newly acquired memory condition with little, if any, contamination of performance by motor debilitation.

\section{Method}

One hundred and two rats (260-480 g) were trained on the PA task and assigned randomly to one of three treatment groups per memory age condition. For the new learning condition, one group of rats received the deep hypothermia treatment immediately after training and one group was returned to the colony without any immersion treatment $(n s=18)$. Both groups were tested $4 \mathrm{~h}$ after training. A third group $(n=12)$ received the deep hypothermia treatment after training but was not tested until $24 \mathrm{~h}$ later to provide a comparison group showing typical levels of amnesia. For the old memory (cue reactivated) condition, three groups of rats $(n s=18)$ were trained on the PA task. Twenty-four hours after training, these subjects received mild hypothermia, deep hypothermia, or no immersion treatment preceded by a brief 30 -sec fearcue exposure. All three of these latter groups were tested $4 \mathrm{~h}$ after cue exposure.

\section{Results and Discussion}

The training response latencies are presented in Table 2. A one-way ANOVA failed to detect any sig-

Table 2

Mean Training Latency (in Seconds) and Posttest Rectal Temperature (in Degrees Centigrade) for all Treatment Groups in Experiment 4

\begin{tabular}{|c|c|c|c|c|c|}
\hline \multirow{2}{*}{$\begin{array}{l}\text { Immersion } \\
\text { Treatment }\end{array}$} & \multirow{2}{*}{$\begin{array}{c}\text { Retention } \\
\text { Interval }\end{array}$} & \multicolumn{2}{|c|}{$\begin{array}{l}\text { Cross-Through } \\
\text { Training } \\
\text { Latency }\end{array}$} & \multicolumn{2}{|c|}{$\begin{array}{c}\text { Posttest } \\
\text { Rectal } \\
\text { Temperature }\end{array}$} \\
\hline & & Mean & SEM & Mean & SEM \\
\hline & & \multicolumn{4}{|c|}{ Newly Acquired Memory } \\
\hline $\begin{array}{l}\text { None } \\
\text { Deep Hypothermia } \\
\text { Deep Hypothermia }\end{array}$ & $\begin{array}{r}4 \\
4 \\
24\end{array}$ & $\begin{array}{r}11.6 \\
10.3 \\
9.0\end{array}$ & $\begin{array}{l}1.90 \\
2.15 \\
1.72\end{array}$ & $\begin{array}{l}36.6 \\
35.3 \\
36.9\end{array}$ & $\begin{array}{l}.11 \\
.33 \\
.18\end{array}$ \\
\hline & & \multicolumn{4}{|c|}{ Old Cue Reactivated Memory } \\
\hline $\begin{array}{l}\text { None } \\
\text { Mild Hypothermia } \\
\text { Deep Hypothermia }\end{array}$ & $\begin{array}{l}4 \\
4 \\
4\end{array}$ & $\begin{array}{r}5.7 \\
10.6 \\
13.3\end{array}$ & $\begin{array}{l}1.69 \\
2.40 \\
3.03\end{array}$ & $\begin{array}{l}36.8 \\
36.6 \\
36.2 \\
\end{array}$ & $\begin{array}{l}.17 \\
.19 \\
.28 \\
\end{array}$ \\
\hline
\end{tabular}




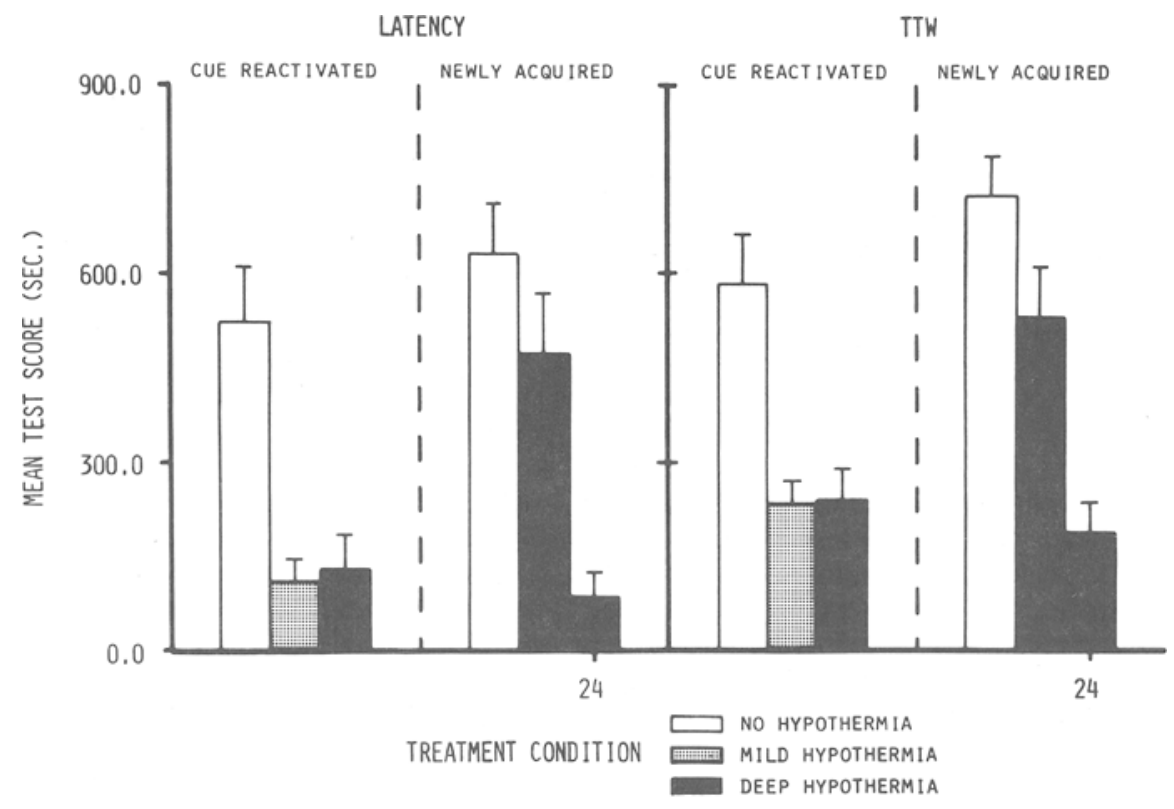

\begin{abstract}
Figure 4. Mean test scores ( \pm SEM) on both latency and TTW measures for the rats of the new and old memory groups $4 \mathrm{~h}$ after deep hypothermia and for the old memory group $4 \mathrm{~h}$ after mild hypothermia. The designation " 24 " indicates a new learning group tested $24 \mathrm{~h}$ after deep hypothermia. Data from nonimmersed controls tested at $4 \mathrm{~h}$ are also shown.
\end{abstract}

nificant differences among the groups prior to the experimental treatments $[\mathrm{F}(5,96)=1.46, \mathrm{p}<.210]$.

The test latency data, illustrated in Figure 4, were analyzed by a one-way ANOVA. An overall significant effect of the experimental manipulation was noted $[F(5,96)=10.58, p<.001]$. Among the new learning groups, subsequent analyses found no significant disruption of performance $4 \mathrm{~h}$ after deep hypothermia treatment, although the typical finding of strong amnesia $24 \mathrm{~h}$ after immersion treatment was obtained $(p<.01)$. This difference in retention as a function of the immersion/test interval was significant $(p<.01)$. For the old cue-reactivated memory groups, both mild and deep hypothermia treatment disrupted retention relative to the nonimmersed controls (ps $<.01$ ). Direct comparison between new and old memory groups indicated no difference in retention $4 \mathrm{~h}$ after training or $4 \mathrm{~h}$ after cue reactivation, but retention test latencies $4 \mathrm{~h}$ after training/ deep-hypothermia were significantly higher than those observed $4 \mathrm{~h}$ after either cue/immersion treatment (ps $<.01)$.

The TTW scores, also shown in Figure 4, confirmed the observations on the latency data. Subsequent analyses of an overall main effect $[F(5,96)=$ $11.49, \mathrm{p}<.001$ ] indicated disruption of memory was evident $24 \mathrm{~h}(\mathrm{p}<.01)$, but not $4 \mathrm{~h}$, after PA training/ deep-hypothermia treatment. The difference between these two cold-water-immersed groups was also significant $(p<.01)$. Among the old cue-reactivated memory groups, both mild and deep immersion treatments produced retention loss within $4 \mathrm{~h}$, with these scores significantly lower than those obtained when deep hypothermia was administered $4 \mathrm{~h}$ after training (ps $<.01)$.

A $2 \times 6$ mixed-design ANOVA, which compared the training and test latencies of each treatment group, indicated significant treatment $[F(5,96)=$ $10.65, \mathrm{p}<.001]$, session $[\mathrm{F}(1,96)=106.87, \mathrm{p}<.001]$, and treatment $\times$ session $[F(5,96)=10.50, p<.001]$ effects. Subsequent analyses demonstrated that the test latencies of the three groups that displayed amnesia were not significantly different from their baseline training levels, suggesting little, if any, residual memory. In contrast, the three groups showing strong retention on the test latency measure all had scores significantly greater than their initial training latencies (ps $<.01$ ).

Analysis of posttest body temperatures (Table 2) indicated a significant difference among the treatment groups $[\mathrm{F}(5,96)=6.87, \mathrm{p}<.001]$. Both the new and old memory groups tested $4 \mathrm{~h}$ after deep hypothermia treatment were slightly, but significantly, depressed relative to nonimmersed controls [body temperature reductions of $3.6 \%(p<.01)$ and $1.6 \%$ $(p<.05)$, respectively]. The body temperature reduction of the train/deep-hypothermia group was also slightly, but significantly, depressed relative to the cue-reactivated/deep-hypothermia group $(p<.05)$.

Thus, the primary finding of the present study was the differential onset of hypothermia-induced amnesia for newly acquired and old cue-reactivated memory. Not only was the retention loss more rapid for the old reactivated memory, but this loss was also found 
for the mild cooling immersion treatment. Both of these observations are consistent with the suggestions of the previous experiments that old reactivated memories may be more vulnerable to disruption than newly acquired memory. The slight, but significant, depressions in body temperature are not plausible explanations for the test performance since deep hypothermia produced differential outcomes at the 4-h test, depending upon the age of the memory. Furthermore, we have shown on several occasions that controls for systemic stress, tested at body temperatures of approximately $30^{\circ} \mathrm{C}$, still exhibit rapid cross-through responding (Hinderliter et al., 1975; Mactutus \& Riccio, 1978; Riccio et al., 1979).

\section{EXPERIMENT 5}

The results of the preceding studies suggested the presence of age-related differences in susceptibility to, and recovery from, hypothermia-induced retrograde amnesia. However, it is possible that the deficits obtained in the old reactivated memory conditions were due to processes other than those producing amnesia for new information. One alternative explanation for retention loss of the reactivated information is based upon retroactive interference. For example, unlike the case with induced amnesia, a distinctive characteristic of retroactive interference paradigms is increased recovery of original learning as a function of time after interpolated treatment (Ceraso \& Henderson, 1965; Silverstein, 1967). While it is difficult to identify the nature of the interference produced by an apparently orthogonal treatment (cold water exposure) upon retention of the PA task, nonspecific forms of retroactive interference have been reported (Wickens, Tuber, Nield, \& Wickens, 1979). If this were the case, any differences between new and old memories in their response to "amnesic" treatment would reflect the influence of different sources of forgetting rather than age-related changes in vulnerability to amnesia. A more distinctive difference between amnesia and interference as sources of forgetting is that the former is characterized by a temporally declining gradient of susceptibility following training, whereas the latter is not clearly influenced by the interval between original learning (or reactivation) and the interpolated task (episode) (Archer \& Underwood, 1951; Newton \& Wickens, 1956). With new learning, hypothermia treatment clearly yields the classic pattern of greater disruption of memory as the training to treatment interval decreases (Riccio, Hodges, \& Randall, 1968; Riccio et al., 1979).

Preliminary evidence discussed by Spear (1976) suggested the gradients for new and old memory facilitation were very comparable through $30 \mathrm{~min}$, yet Gordon (1977a) noted, for a similar experiment, that the reactivation gradient was steeper than the original learning gradient. In both cases, however, the comparisons were made across experiments. As a host of variables have been noted to influence the slope of the gradient (Mah \& Albert, 1973), any attempt to compare gradients would be more meaningful when done within the same experiment, thereby providing implicit control for a number of potentially confounding variables.

The present design included conditions to compare directly the effects of deep hypothermia on both new and old memories across four treatment delay intervals. A similar temporal examination of the effect of mild cooling on old memory was also included.

\section{Method}

One hundred and forty-four rats (250-500 g) were given PA training and divided randomly into 12 groups $(n s=12)$. Four groups were assigned to the new learning condition and received deep hypothermia treatment $.5,5,10$, or 30 min following training footshock. To assess the gradient of disruptibility for old reactivated memories, $24 \mathrm{~h}$ after PA training two additional sets (four groups each) of rats were administered either prolonged $(10 \mathrm{~min})$ or brief $(3 \mathrm{~min})$ cooling $.5,5,10$, or $30 \mathrm{~min}$ after a 30 -sec cue exposure treatment. For the .5-min delay interval, the hypothermia treatments were administered as soon as possible after training or memory reactivation. For all other delay intervals, the animals were maintained for the assigned period in a standard housing cage within the experimental room. Retention was measured $24 \mathrm{~h}$ after cold water immersion.

\section{Results and Discussion}

Mean ( \pm SEM) training latencies ranged from 5.2 to $12.7 \mathrm{sec}$ for all groups. A one-way ANOVA found no significant difference among these training scores $[\mathrm{F}(11,132)<1.00]$.

The test latency data $( \pm$ SEM), illustrated in Figure 5 , are plotted as a function of immersion treatment delay interval. A $3 \times 4$ ANOVA on the test latency data for the three memory-age/hypothermiatreatment conditions across the four delay intervals indicated a marginal memory-age/hypothermiatreatment effect $[F(2,132)=2.82, p<.062]$ and a clear immersion treatment delay effect $[F(3,132)=$ $24.11, \mathrm{p}<.001$ ]. The failure to obtain a significant experimental treatment $\times$ immersion delay interaction indicated that all three memory-age/hypothermiatreatment conditions showed increasing resistance to disruption with the passage of time. Since our primary concern was the comparability of the time course of vulnerability for newly acquired and old reactivated memories, direct comparisons between these memories of different ages subjected to deep hypothermia were undertaken. For the new learning condition, there were strong disruptive effects of deep hypothermia at all delays through $10 \mathrm{~min}$ relative to the 30 -min interval (ps $<.01$ ). In contrast, for the old reactivated memory, only the most immediate deep hypothermia treatment produced impairment of memory relative to that obtained at the 30 min interval $(p<.01)$. Direct comparison across the 


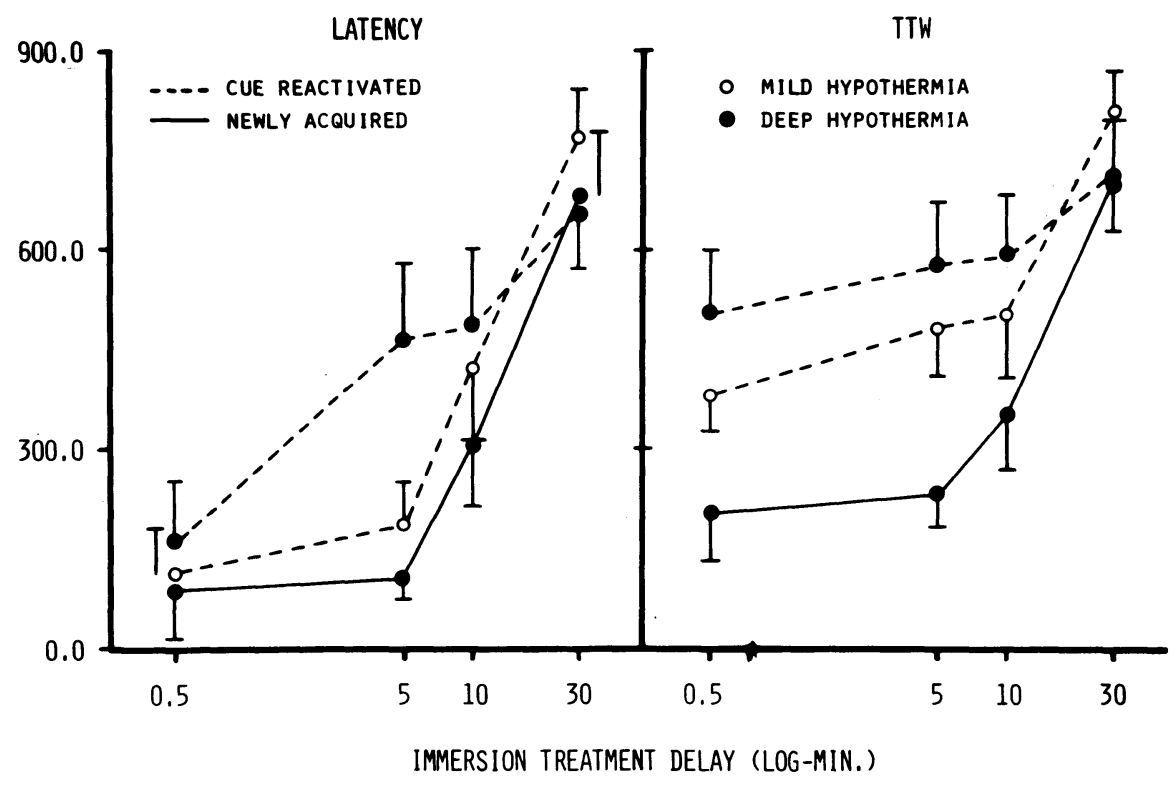

\begin{abstract}
Figure 5. Mean test scores $( \pm$ SEM) on both latency and TTW measures for the rats of the new and old memory groups following deep hypothermia and for the old memory group following mild hypothermia as a function of the delay between the acquisition or cue reactivation of memory and the cooling immersion treatment.
\end{abstract}

gradients obtained following deep hypothermia indicated the two classes of memories differed in their retention scores only at the 5-min delay interval $(\mathrm{p}<.02)$.

A similar $3 \times 4$ ANOVA on the TTW index found robust memory-age/hypothermia-treatment $[\mathrm{F}(2,132)$ $=8.43, \mathrm{p}<.001]$ and immersion delay $(\mathrm{F}(2,132)=$ $13.28, \mathrm{p}<.001]$ effects. For the newly acquired memory, strong disruptive effects of deep hypothermia were again apparent through a 10-min delay relative to the 30 -min interval (ps $<.01$ ). For animals in the old reactivated memory condition subjected to deep hypothermia, the TTW means were ordered in terms of greater resistance to disruption with longer delay intervals, but no group differences were statistically confirmed. Direct comparison between new and old memory gradients indicated significantly greater resistance to disruption for the old reactivated memory when the deep hypothermia treatment was administered immediately $(.5 \mathrm{~min}, \mathrm{p}<.05)$ or after a short delay interval $(5 \mathrm{~min}, \mathrm{p}<.01)$.

Thus, the latency data suggested that old memory, like new learning, becomes increasingly resistant to disruption with the passage of time, although the susceptibility of the old reactivated memory may follow a rather abbreviated time course. While this outcome is at odds with a retroactive interference interpretation, the failure to obtain a reliable gradient on the TTW measure for the cue reactivated memory suggested that the old memory also displays some resistance to disruption even immediately after reactivation. The relatively flat gradient seen with this index would not be inconsistent with an interference notion.

If memory loss was attributable to interference and not amnesia, then a mild cold water immersion of equal surprise, but more limited physiological consequence, should act similarly to deep hypothermia. As is illustrated in Figure 5, the disruption of old reactivated memory by mild cooling does not clearly support either position. The effect of mild hypothermia on the test latency scores of the old reactivated memory groups appeared to follow a time course parallel to that of the new-learning/deephypothermia condition. The old memory groups displayed severe retention deficits when reactivation was followed either immediately or after a 5-min delay by brief whole-body cooling (ps $<.01)$. When brief immersion was delayed 10 min after reactivation, it produced greater disruption than when delayed $30 \mathrm{~min}$ $(p<.01)$, yet at the same time the memory was less affected than when cooling occurred either immediately $(p<.05)$ or 5 min after reactivation $(p<.07)$. Comparisons among the three gradients suggested that, with the 5-min delay condition, mild cooling produced significantly more disruption than deep cooling for a similar old reactivated memory $(p<.03)$, and that this disruptive effect of mild cooling on old memory was not different from that produced by the deep hypothermia treatment administered after new learning.

With respect to TTW scores, the effect of mild hypothermia on an old reactivated memory appeared to follow a time course similar to that of the old- 
memory/deep-hypothermia condition. The disruption of old memory by mild cooling was not statistically different from that provided by deep cooling at any delay interval. However, unlike the effects of deep hypothermia, significant disruption of old memory by mild cooling was found through delays of $10 \mathrm{~min}$ relative to the 30 -min interval (ps $<.01$ ). Comparisons among the three TTW gradients suggested, contrary to the latency measure, that old reactivated memory showed greater resistance to disruption when subjected to either mild or deep hypothermia after a 5-min delay than did new learning subjected to deep hypothermia after a similar delay.

To evaluate the magnitude of the induced memory deficits, the training and test latencies for each of the 12 groups were subjected to a $2 \times 12$ mixed-design ANOVA. Subsequent analyses of the significant interaction between groups and session $[F(11,132)=$ $7.70, \mathrm{p}<.001$ ] indicated that no differences in latencies could be detected for any of the groups subjected to immediate immersion treatment, for the 5-min new-learning/deep-hypothermia group, or the 5-min old-memory/mild-hypothermia group. Thus, there was no evidence of residual memory in these conditions. However, strong retention was evidenced in all the remaining groups (ps $<.01)$.

The mean ( \pm SEM) posttest body temperatures for all groups ranged from $36.0^{\circ}$ to $36.9^{\circ} \mathrm{C}$. A one-way ANOVA suggested that there were no differences among the groups at the time of testing $[F(11,132)$ $<1.00]$.

In summary, the latency data indicated that both old and new memories become increasingly resistant to disruption over time and, under some conditions, the susceptibility of the old reactivated memory is rather transient. The more conservative TTW index also suggested that both classes of memory become increasingly resistant to disruption over time and that, under some conditions, the old memory will display some resistance to disruption even immediately after reactivation. These findings, while not definitive, appear to support the view that the memory deficits reflect a retrograde effect common to both new and old information.

\section{EXPERIMENT 6}

A more compelling demonstration that the amnesia for old reactivated memory is not a form of retroactive interference would be provided if the target memory could be recovered by reexposing subjects to the earlier amnesic treatment (i.e., the putative source of interference). It has been well established that retrograde amnesia may be reversed by providing some of the cues that presumably were stored with, and therefore should provide access to, the memory of the original training episode. We have found that when amnesia is induced by hypothermia treatment immediately after training, access to memory may be facilitated by recooling subjects prior to testing (Hinderliter et al., 1975; Mactutus, McCutcheon, et al., 1980; Mactutus \& Riccio, 1978; Riccio et al., 1979). A parallel finding of amnesia following ECS treatment has also been documented (Thompson \& Grossman, 1972; Thompson \& Neely, 1970). Although retroactive interference can also be reversed, neither logic nor data would lead one to expect that reexposure to the interfering material would alleviate the impairment of the memory for the original learning.

Thus, the final experiment was designed to investigate whether a reminder treatment would be effective in reversing the deficits observed for old active memories following deep or mild hypothermia and also to clarify the possible role of interference in the retention decrements induced by the cooling treatments.

\section{Method}

Sixty-three rats (320-400 g) were trained on the PA task and assigned randomly to treatment conditions. A new learning condition $(n=18)$ received deep hypothermia treatment within $30 \mathrm{sec}$ of footshock termination, while the old memory condition received their hypothermia treatment (mild hypothermia for 18 subjects, deep hypothermia for 18 additional subjects) following a brief 30 -sec fear cue exposure $24 \mathrm{~h}$ after avoidance training. The rats in each condition were tested $24 \mathrm{~h}$ after hypothermia treatment, with one-half of each group receiving a recooling (reminder) treatment $2 \mathrm{~h}$ prior to their retention test. The specific details of the recooling treatment were similar to those of the hypothermia treatments, with the exception that the animals were immersed for $8 \mathrm{~min}$ or until their body temperatures had fallen to $25^{\circ} \mathrm{C}$ or below. Upon rewarming to $29^{\circ}-31^{\circ} \mathrm{C}$ body temperature (approximately $2 \mathrm{~h}$ ), the recooled subjects were tested.

Nine additional animals received hypothermia treatment immediately after PA training and a recooling immersion $2 \mathrm{~h}$ prior to a retention test $48 \mathrm{~h}$ after original training. The recooling treatment for a 48-h-old memory was employed to assess any difference between the reminder groups attributable to the age of the memory.

\section{Results and Discussion}

Table 3 presents the mean $( \pm$ SEM) initial response latencies for all groups. No significant difference among the response latencies was observed prior to the experimental treatments $[F(6,56)<1.00]$.

Since the retention scores for the two new learning groups that received the recooling treatment either 24 or $48 \mathrm{~h}$ after hypothermia treatment were comparable on both the latency $[F(1,16)<1.00]$ and TTW $[\mathrm{F}(1,16)<1.00]$ indices (mean latency, $\pm \mathrm{SEM}$, 578.9 $\pm 103.0,652.2 \pm 92.8$, and mean TTW, 714.0 $\pm 61.3,681.9 \pm 78.3$, for the $24-$ and 48 -h groups, respectively), these scores were pooled to provide a balanced design for subsequent analyses. This facilitation of memory recovery by a reminder treatment 24 or $48 \mathrm{~h}$ after original learning and hypothermia treatment suggested that any difference obtained in the induced recovery for new vs. old memories could not be attributed to the age of the memory. 
Table 3

Mean Training Latency (in Seconds) and Posttest Rectal Temperature (in Degrees Centigrade) for all Treatment Groups in Experiment 6

\begin{tabular}{cccccc}
\hline & \multicolumn{3}{c}{$\begin{array}{c}\text { Cross-Through } \\
\text { Training } \\
\text { Latency }\end{array}$} & & \multicolumn{2}{c}{$\begin{array}{c}\text { Posttest } \\
\text { Rectal } \\
\text { Temperature }\end{array}$} \\
\cline { 3 - 3 } \cline { 5 - 6 } $\begin{array}{c}\text { Post- } \\
\text { immersion }\end{array}$ & $\begin{array}{c}\text { Treat- } \\
\text { ment }\end{array}$ & Mean & SEM & Mean & SEM \\
\hline \multicolumn{5}{c}{ Newly Acquired Memory/Deep Hypothermia } \\
$24 \mathrm{~h}$ & $\mathrm{~N}$ & 9.2 & 3.40 & 36.6 & .14 \\
$24 \mathrm{~h}$ & $\mathrm{Y}$ & 6.4 & 1.48 & 32.6 & $.33^{*}$ \\
$48 \mathrm{~h}$ & $\mathrm{Y}$ & 10.2 & 2.51 & & \\
\multicolumn{5}{c}{ Old Cue Reactivated Memory/Deep Hypothermia } \\
$24 \mathrm{~h}$ & $\mathrm{~N}$ & 12.6 & 2.33 & 36.0 & .17 \\
$24 \mathrm{~h}$ & $\mathrm{Y}$ & 11.9 & 4.00 & 32.5 & .53 \\
\multicolumn{5}{c}{ Old Cue Reactivated Memory/Mild Hypothermia } \\
$24 \mathrm{~h}$ & $\mathrm{~N}$ & 9.1 & 3.58 & 36.1 & .18 \\
$24 \mathrm{~h}$ & $\mathrm{Y}$ & 8.3 & 1.54 & 32.9 & .39 \\
\hline
\end{tabular}

Note- "Treatment" refers to recooling treatment $(N=n o$; $Y=y e s)$. $P o o l e d$ for 24- and 48- $h$ groups.

Figure 6 shows the mean test latencies ( \pm SEM) of the three memory-age/hypothermia-treatment conditions with or without a prior reminder treatment. A $3 \times 2$ ANOVA indicated reliable effects only for the reminder treatment $[F(1,57)=21.68, p<.001]$. For the new learning condition, as expected, the reminder treatment was effective in reversing the amnesic deficit $(p<.05)$. For the old memory groups, regardless of whether the memory loss was induced by mild or deep cooling, the recooling procedure markedly enhanced test performance (ps $<.01)$. Furthermore, no significant differences were noted among any of the recooled groups or any of the nonrecooled groups.

With respect to the TTW measure, again only a significant reminder effect was obtained on a $3 \times 2$ ANOVA $[\mathrm{F}(1,57)=24.50, \mathrm{p}<.001]$. A pattern identical to that detected with the latency measure was observed, with each of the groups receiving the reminder treatment displaying stronger retention than their nonrecooled counterparts (ps $<.03$ ).

A $3 \times 2$ ANOVA on posttest body temperature (Table 3) found slight, but significant, depressions on this measure as a function of the recooling reminder treatment $[F(1,57)=13.42, p<.001]$. Subsequent analyses indicated that each recooled group was significantly cooler than its nonrecooled counterpart (ps $<.01)$, but there were no differences among the recooled groups or among the nonrecooled groups. Although controls for the effects of systemic stress on performance were not included here, it has been demonstrated repeatedly that, following the induction of amnesia, a recooling treatment genuinely facilitates memory retrieval and does not merely reflect any debilitating effects of the cold-water immersion (Hinderliter et al., 1975; Mactutus \& Riccio, 1978; Riccio et al., 1979; Mactutus, Riccio, \& Rogers, Note 3).

These observations provide rather clear evidence that the cooling-induced loss of the old reactivated memory is a genuine amnesic effect rather than a

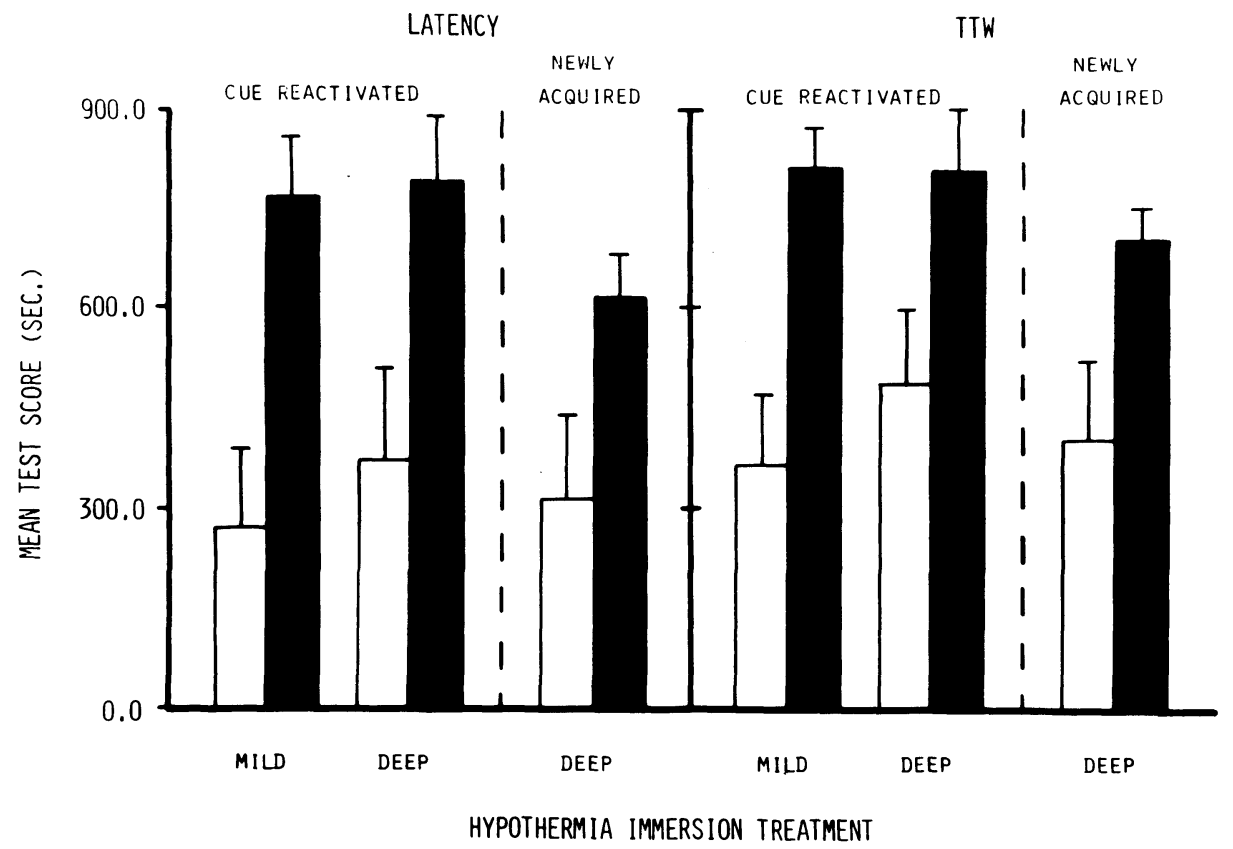

Figure 6. Mean test scores $( \pm$ SEM) on both latency and TTW measures for the rats of the new and old memory groups following deep hypothermia and for the old memory group following mild hypothermia after recooling (dark bars) or no recooling (light bars) $2 \mathrm{~h}$ prior to testing. 
form of retroactive interference. It should also be noted, however, that the baseline of retention loss was not as robust as in the preceding studies. A $6 \times 2$ mixed-design ANOVA comparing training and test latencies indicated a significant session effect $[F(1,57)$ $=156.30, \mathrm{p}<.001]$. Subsequent analyses suggested that none of the amnesias were "complete," since the test scores had not returned to their respective baseline levels (ps <.02). While some (Cherkin, 1972; Gold \& King, 1974) have argued that effective reminder treatments are obtained only because amnesic treatments are incomplete, there are some empirical data showing that the greater the residual memory is following deep hypothermia treatment, the less the effectiveness of a recooling reminder treatment (Riccio et al., 1979). This finding, consistent with a "contextual cues" interpretation of amnesia (Hinderliter et al., 1975), suggests that the present results might reflect a conservative estimate of the reversibility of retrograde amnesia for old memory.

\section{GENERAL DISCUSSION}

The findings of the present series of experiments are consistent with earlier reports that old reactivated memories share some of the characteristics of new memories. For example, in accord with the original demonstrations using ECS treatment (cf. Misanin et al., 1968; Schneider \& Sherman, 1968), we found that old memory, when reactivated by cue exposure, was disrupted by deep hypothermia treatment. Moreover, the severity of amnesia was similar to that produced in new memory. Davis and Klinger (1969) have also reported what appears to be an instance of amnesia for old memory. They found that administration of agents such as potassium chloride, puromycin, or acetoxycloheximide $24 \mathrm{~h}$ after training, but preceded by a reexposure to the training apparatus, resulted in impaired retention. Thus, a variety of agents seem capable of inducing amnesia for established information.

These findings add to a growing body of evidence that the level of activity of memory, rather than its age, is a primary determinant of the modifiability of target information (Lewis, 1979). For example, using quite different paradigms, Gordon and his colleagues (Gordon, 1977a; Gordon \& Spear, 1973b) have conducted a series of experiments showing that both new and old (cued) memories may be enhanced by strychnine sulfate. Furthermore, with respect to competition between memories (cf. Spear, 1971), they have shown that old memory, when reactivated, may exert an interference effect on retention comparable to that produced by a new task (Gordon, 1977b; Gordon \& Feldman, 1978; Gordon et al., 1979; Gordon \& Spear, 1973a). Recent work in our lab has extended these observations by demonstrat- ing the malleability of old information through a procedure akin to counterconditioning; modification was not produced, however, unless the memory was reactivated (Richardson, Riccio, Jamis, Cabosky, \& Skoczen, in press).

While it is parsimonious to maintain that new and old memories share similar characteristics, the present data imply that there may be some age-related changes in the characteristics of memory. For example, old reactivated memories were susceptible to disruption by a mild stress agent, brief cold-water immersion, which had no discernible effect on new learning when administered immediately after training (Experiment 1) or when a brief 30-sec cue exposure was interpolated between acquisition and mild cooling (Experiment 3). While the lack of effect of mild cooling on newly acquired memory agrees with previous literature (Grosser \& Percy, 1971; Marlin et al., 1978; Riccio et al., 1968), the effect of a mildly stressful agent on old active memory has not previously been documented. Although this greater susceptibility to disruption of the old reactivated memory did not generalize to a second mildly stressful agent, brief hyperthermia, it is difficult to choose a scale on which to equate the consequences of cold and warm water immersion. Perhaps most importantly, however, the amnesia for old memory induced by mild hypothermia was rather substantial and consistent across each of the experiments. Thus, there may be a boundary condition on Ribot's concept of memory disruptability: although early memories may be more resistant to disruption than new ones, an old reactivated memory under some conditions appears to be highly vulnerable. That old memory may be more malleable in certain respects than new information is supported by the differences in onset of amnesia (Experiment 4). While retention of passive avoidance remained strong several hours after amnesic treatment in the new learning groups, a finding consistent with earlier research (Geller \& Jarvik, 1968; Mactutus \& Riccio, 1978), severe memory loss was observed at the same interval in the reactivated groups subjected to either deep or mild cooling.

Interestingly, the notion that old reactivated memory may have greater vulnerability than newly acquired memory suggests an interpretation of an otherwise perplexing aspect of an important study by Howard, Glendenning, and Meyer (1974). In that research, rats were trained on three successive twochoice discriminations. The first and third problems were learned to avoid shock, designated as S1 and S3, while the second was learned to obtain food reward, F2. When ECS was administered immediately after mastery of the third problem, retention of the S1 habit, learned under a motivational state common to that existing at the time of ECS treatment, was disrupted, but neither the F2 nor the S3 habit was impaired. The puzzle has been why the most recent 
(S3) learning was not disrupted also. Given the findings reported here, it does not seem unreasonable to suggest that the old memory, S1, was reactivated during acquisition of Task S3, and thereby subject to disruption by an agent that was not quite severe enough to produce amnesia for the new habit. Of further interest is the fact that Howard et al. (1974) found that if ECS was delayed 3 days after S3 acquisition, but preceded by a single warm-up trial, retrograde amnesia was then produced. As in the present study, it appears that the vulnerability of the S3 habit increased over the 3-day retention interval such that, following a "reactivation" (warm-up) trial, the memory was susceptible to disruption by ECS.

While it has long been known that new learning displays a temporally graded decrease in susceptibility to amnesic treatment (McGaugh, 1966), little information has been available about this aspect of reactivated memory. However, the present data and some previous evidence (e.g., DeVietti \& Kirkpatrick, 1976) indicate that a reactivated memory does not remain permanently vulnerable to amnesic treatment but, rather, becomes increasingly resistant to disruption. Whether the reactivated episode subsides to an invulnerable status at the same rate as new learning is an issue that remains not fully answered. It appears that under some conditions the gradient of hypothermia-induced amnesia was steeper following cuing reactivation than original acquisition; a similar observation has been noted when anisomycin was employed as the amnesic agent (Judge et al., Note 1). These findings, in conjunction with the sharper gradient obtained in modulating old memory with strychnine (Gordon, 1977a; but see also DeVietti, Conger, \& Kirkpatrick, 1977) tempt us to conclude that the duration of processing after a reactivation exposure may be shorter than following new learning. Substantiation of this point would, of course, indicate a dimension along which old memory can be viewed as less vulnerable than new learning.

The multidimensional nature of vulnerability to amnesia is reflected also in the fact that old reactivated information, after being suppressed by amnesia treatment, tends to return more readily than newly acquired learning and, in that sense, appears more "durable." For example, Experiment 2 indicated that, for the old memory condition, amnesia was transient in the face of repeated testing sessions, whereas the new learning group showed a more enduring memory failure. Employing a K-maze in an appetitive discrimination task, DeViettiand Zwanziger (1975) noted that ECS-induced amnesia for old memory is short-lived relative to that for new learning. Although an attempted replication failed to obtain evidence for the spontaneous return of old reactivated memory (Bregman et al., 1976), others have found that anisomycin injected immediately after training induced a persistent amnesia, but only a temporary (48-h) amnesia after a reactivation treatment (Judge et al., Note 1). Consistent with this greater durability of old reactivated memory, Spear and his associates (Spear, Hamberg, \& Bryan, 1980) have noted that forgetting may be more rapid following original learning than following a temporally remote reactivation treatment.

As suggested earlier, it seems very unlikely that these differences between old and new memory following hypothermia can be explained on the basis of different underlying mechanisms (i.e., retroactive interference vs. amnesia). The temporal gradients of loss for both ages of memory are not easily consistent with traditional interference theory. While the recent distinction between trace and process interference, that is, between interference with stored information or with processes involved in the input/output of material (Runquist, 1975), might predict a graded function, the induced recovery of memory by a second exposure to the interpolated event makes an interference approach untenable.

We have previously presented (Hinderliter et al., 1975; Mactutus \& Riccio, 1978) and tested (Mactutus, McCutcheon, et al., 1980; Mactutus \& Riccio, 1978; Riccio et al., 1979) a retrieval-oriented "contextual cues" explanation of hypothermia-induced retrograde amnesia that may also provide a useful framework for understanding differences in memory loss between reactivated and newly acquired learning. In brief, and in common with consolidation views (e.g., McGaugh \& Dawson, 1971), processing is assumed to continue following the nominal training trial (e.g., Wagner, Rudy, \& Whitlow, 1973). However, rather than being destroyed by the amnesic event, traces or attributes of the target episode would become encoded in terms of the immediate postacquisition state or context (e.g., hypothermia). When these cooling cues are absent at testing, as is the usual situation, an important source of retrieval cues is missing from the environment, resulting in amnesia. Recooling subjects prior to testing reestablishes the thermal and/or other cues of the internal milieu that permit retrieval of memory; that is, recovery from the amnesia occurs. (Those familiar with the genre of mystery novels in which the sole witness to a crime is rendered amnesic by a blow to the head, but at the critical moment regains his/her memory following a second, inadvertent, concussive event, will recognize why this explanation has been dubbed the "twobump" theory.) With respect to amnesia for old memory, we assume that cuing results in retrieval of the original information, and that several attributes of the reactivated memory become reencoded in terms of the current context of the organism.

This approach has the virtue of predicting temporal gradients for both classes of memory, since fewer 
new or retrieved attributes would become embedded in the hypothermic context with increasing delays of treatment. The induced recovery from amnesia would also be expected for both conditions. More interestingly, the model may help to account for some of the differences in amnesia between old and new memory, as well as for the fact that in the reactivation/hypothermic conditions the measure of time on safe side sometimes reflected less memory impairment than did the latency index. For example, when amnesic treatment occurs after initial acquisition, subsequent access to the target information may be limited to the contextual state and a few of the more salient attributes of the original training procedure. Recovery induced by recooling, but not by repeated testing, thus would be anticipated. In contrast, when old reactivated memory is followed by an amnesic insult, the original storage/processing remains intact; only the retrieved attributes are reencoded. With repeated tests, access to memory might still be possible through some of the attributes encoded in the normal state at original training. A similar analysis seems applicable to the observation that the TTW measure typically reflected higher levels of retention than the latency index for subjects showing amnesia for old memory. We suspect that the execution of the crossthrough response provided an implicit and salient reactivation cue for the animals in the cuing/hypothermia condition, since their initial processing was intact. The same response may have had little value for the new learning groups in which initial processing immediately became encoded in the altered contextual state. Although additional ad hoc assumptions might explain the differential effectiveness of a mild stressor treatment with old and new learning, such elaboration seems premature at this time. More generally, however, it appears that memory reactivation involves processes differing in temporal dynamics and sensitivity to modification compared with those of initial memory formation. But, common to the amnesias for both new and old learning is a striking persistence of the original information.

\section{REFERENCE NOTES}

1. Judge, M. E., Haraczkiewicz, E., \& Quartermain, D. Qualitative differences in the induction of amnesia by protein synthesis inhibition following original training or a reactivation treatment. Paper presented at the meeting of the Eastern Psychological Association, Philadelphia, 1979.

2. Gordon, W. C. Mechanisms underlying cue-induced retention enhancement. In Memory mechanisms in animal behavior. Symposium presented at SUNY at Binghamton, June 1980.

3. Mactutus, C. F., Riccio, D. C., \& Rogers, P. D. Memory reactivation with internal cues: Persistence over multiple treatments. Paper presented at the meeting of the American Psychological Association, New York, 1979.

\section{REFERENCES}

Ader, R., Weijnen, J. A. W. M., \& Moleman, P. Retention of a passive avoidance response as a function of the intensity and duration of electric shock. Psychonomic Science, 1972, 26, 125-128.

Archer, E. J., \& Underwood, B. J. Retroactive inhibition of verbal associations as a multiple function of temporal point of interpolation and degree of interpolated learning. Journal of Experimental Psychology, 1951, 42, 283-290.

Banker, G., Hunt, E., \& Pagano, R. Evidence supporting the memory disruption hypothesis of electroconvulsive shock action. Physiology \& Behavior, 1969, 4, 895-899.

Bregman, N., Nicholas, T., \& Lewis, D. J. Cue-dependent amnesia: Permanence and memory return. Physiology \& Behavior, 1976, 17, 267-270.

Ceraso, J., \& Henderson, A. Unavailability and associative loss in RI and PI. Journal of Experimental Psychology, 1965, 70, 300-303.

Cherkin, A. Retrograde amnesia in the chick: Resistance to the reminder effect. Physiology \& Behavior, 1972, 8, 949-955.

Cronholm, B., \& Lagergren, A. Memory disturbances after eiectroconvulsive therapy. 3. An experimental study of retrograde amnesia after electroconvulsive shock. Acta Psychiatrica et Neurologica Scandinavica, 1959, 3, 283-310.

Davis, R. E., \& Agranoff, B. W. Stages of memory formation in goldfish: Evidence for an environmental trigger. Proceedings of the National Academy of Sciences, 1966, 55, 555-559.

Davis, R. E., \& Hirtzel, M. S. Environmental control of ECSproduced retrograde amnesia in goldfish. Physiology \& Behavior, 1970, 5, 1089-1092.

DAVIS, R. E., \& KLINGER, P. D. Environmental control of amnesic effects of various agents in goldfish. Physiology \& Behavior, 1969, 4, 269-271.

Dawson, R. G., \& McGAügh, J. L. Electroconvulsive shock effects on a reactivated memory trace: Further examination. Science, 1969, 166, 525-527.

DeVietti, T. L., Conger, G. L., Kirkpatrick, B. R. Comparison of the enhancement gradients of retention obtained with stimulation of the mesencephalic reticular formation after training or memory reactivation. Physiology \& Behavior, 1977, 19, 549-554.

DeVietTi, T. L., \& Holliday, J. H. Retrograde amnesia produced by electroconvulsive shock after reactivation of a consolidated memory trace: A replication. Psychonomic Science, 1972, 29, 137-138.

DeVietTi, T. L., Holliday, J. H., \& Larson, R. C. Comparison of amnesias induced by electroconvulsive shock administration after training-trial footshock or noncontingent footshock in rats. Journal of Comparative and Physiological Psychology, 1973, 84, 579-585.

DeVietTi, T. L., \& KirkPatrick, B. R. The amnesia gradient: Inadequate as evidence for a memory consolidation process. Science, 1976, 194, 438-439.

DeVietti, T. L., \& LARSon, R. C. ECS effects: Evidence supporting state-dependent learning in rats. Journal of Comparative and Physiological Psychology, 1971, 74, 407-415.

DeVietti, T. L., \& ZwAnziger, M. D. Some properties of ECSinduced amnesia for a long-term habit. Physiological Psychology, 1975, 3, 340-344.

Duncan, C. P. The retroactive effect of electroshock on learning. Journal of Comparative and Physiological Psychology, 1949, 42, 32-44.

Frankel, F. H. Current perspectives on ECS: A discussion. American Journal of Psychiatry, 1977, 134, 1014-1019.

Geller, A., \& JARVIK, M. E. The time relations of ECS induced amnesia. Psychonomic Science, 1968, 12, 169-170.

Gerson, R., \& Hende rson, R. W. Conditions that potentiate the effects of electroconvulsive shock administered 24 hours after avoidance training. Animal Learning \& Behavior, 1978, 6, 346-351.

Glickman, S. E. Perseverative neural processes and consolidation of the memory trace. Psychological Bulletin, 1961, 58, 218-233.

Gold, P. E., \& KING, R. A. Amnesia: Tests of the effect of delayed footshock-electroconvulsive shock pairings. Physiology \& Behavior, 1972, 8, 797-800. 
Gold, P. E., \& King, R. A. Retrograde amnesia: Storage failure versus retrieval failure. Psychological Review, 1974, 81, 465-469.

Gordon, W. C. Susceptibility of a reactivated memory to the effects of strychnine: A time-dependent phenomenon. Physiology \& Behavior, 1977, 18, 95-99. (a)

Gordon, W. C. Similarities of recently acquired and reactivated memories in interference. American Journal of Psychology, 1977, 90, 231-242. (b)

Gordon, W. C., \& Feldman, D. T. Reactivation-induced interference in a short-term retention paradigm. Learning and Motivation, 1978, 9, 164-178.

Gordon, W. C., Frankel, S. E., \& Hamberg, J. M. Reactivation induced proactive interference in rats. American Journal of Psychology, 1979, 92, 693-702.

Gordon, W. C., \& Spear, N. E. Effect of reactivation of a previously acquired memory on the interaction between memories in the rat. Journal of Experimental Psychology, 1973, 99, 349-355. (a)

Gordon, W. C., \& Spear, N. E. The effects of strychnine on recently acquired and reactivated passive avoidance memories. Physiology \& Behavior, 1973, 10, 1071-1075. (b)

Grosser, G. S., \& Percy, H. E. Postshock immersion of mice without memory disruption. Journal of Comparative and Physiological Psychology, 1971, 76, 119-122.

Невв, D. O. The organization of behavior. New York: Wiley, 1949.

Herz, M. J., \& Peeke, H. V. S. Permanence of retrograde amnesia produced by electroconvulsive shock. Science, 1967, 156, 1396-1397.

Herz, M. J., \& Peeke, H. V. S. ECS-produced retrograde amnesia: Permanence versus recovery over repeated testing. Physiology \& Behavior, 1968, 3, 517-521.

Hinderliter, C. F., Webster, T., \& Riccio, D. C. Amnesia induced by hypothermia as a function of treatment-test interval and recooling in rats. Animal Learning \& Behavior, 1975, 3, 257-263.

Howard, R. L., Glendenning, R. L., \& Meyer, D. R. Motivational control of retrograde amnesia: Further explorations and effects. Journal of Comparative and Physiological Psychology, 1974, 86, 187-192.

Jacobs, B. L., \& Sorenson, C. A. Memory disruption in mice by brief posttrial immersion in hot or cold water. Journal of Comparative and Physiological Psychology, 1969, 68, 239-244.

Jamieson, J. L., \& Albert, D. J. Amnesia from ECS: The effect of pairing ECS and footshock. Psychonomic Science, 1970, 18, 14-15.

KANE, J., \& JARVIK, M. E. Amnesia effects of cooling and heating in mice. Psychonomic Science, 1970, 18, 7-8.

King, R. A., \& Glasser, R. L. Duration of electroconvulsive shock-induced retrograde amnesia in rats. Physiology \& Behavior, 1970, 5, 335-339.

Koppenaal, R. J., Jagoda, E., \& Cruce, J. A. F. Recovery from ECS-produced amnesia following a reminder. Psychonomic Science, 1967, 9, 293-294.

LEwIs, D. J. Sources of experimental amnesia. Psychological Review, 1969, 76, 461-472.

LEwIS, D. J. A cognitive approach to experimental amnesia. American Journal of Psychology, 1976, 89, 51-80.

LEwIs, D. J. Psychobiology of active and inactive memory. Psychological Bulletin, 1979, 86, 1054-1083.

Lewis, D. J., Miller, R. R., \& Misanin, J. R. Control of retrograde amnesia. Journal of Comparative and Physiological Psychology, 1968, 66, 1547-1549.

Lewis, D. J., Miller, R. R., \& Misanin, J. R. Selective amnesia in rats produced by electroconvulsive shock. Journal of Comparative and Physiological Psychology, 1969, 69, 136-140.

MaCtutus, C. F. Hypothermia-induced retrograde amnesia: Temperature independent onset and temperature dependent alleviation. Unpublished master's thesis, Kent State University, 1977.
Mactutus, C. F., Ferek, J. M., \& Riccio, D. C. Amnesia induced by hyperthermia: An unusually profound, yet reversible, memory loss. Behavioral and Neural Biology, 1980, 30, 260-277.

Mactutus, C. F., McCutcheon, K., \& Riccio, D. C. Body temperaturecues as contextual stimuli: Modulation of hypothermiainduced retrograde amnesia. Physiology \& Behavior, 1980, 25, 875-883.

Mactutus, C. F., \& Riccio, D. C. Hypothermia-induced retrograde amnesia: Role of body temperature in memory retrieval. Physiological Psychology, 1978, 6, 18-22.

Mactutus, C. F., Riccio, D. C., \& Ferek, J. M. Retrograde amnesia for old (reactivated) memory: Some anomalous characteristics. Science, 1979, 204, 1319-1320.

Mactutus, C. F., Smith, R. L., \& Riccio, D. C. Extending the duration of ACTH-induced memory reactivation in an amnesic paradigm. Physiology \& Behavior, 1980, 24, 541-546.

MAH, C. J., \& AlberT, D. J. Electroconvulsive shock-induced retrograde amnesia: An analysis of the variation in the length of the amnesia gradient. Behavioral Biology, 1973, 9, 517-540.

Marlin, N. A., Greco, C., \& Miller, R. R. Effects of posttraining reinforcement upon retention of a passive avoidance task. Bulletin of the Psychonomic Society, 1978, 11, 295-297.

Masterson, F. A., \& Campbell, B. A. Techniques of electric shock motivation. In R. D. Myers (Ed.), Methods in psychobiology (Vol. 2). New York: Academic Press, 1972.

McGaugh, J. L. Time-dependent processes in memory storage. Science, 1966, 153, 1351-1358.

McGaugh, J. L., \& Dawson, R. G. Modification of memory storage processes. In W. K. Honig \& P. H. R. James (Eds.), Animal memory. New York: Academic Press, 1971.

McGaugh, J. L., \& Herz, M. J. Memory consolidation. San Francisco: Albion, 1972.

Mille R, R. R., \& Springer, A. D. Induced recovery of memory in rats following electroconvulsive shock. Physiology \& Behavior, 1972, 8, 645-651.

Miller, R. R., \& Springer, A. D. Amnesia, consolidation, and retrieval. Psychological Review, 1973, 80, 69-79.

Miller, R. R., \& Springer, A. D. Implications of recovery from experimental amnesia. Psychological Review, 1974, 81, 470-473.

Misanin, J. R., Miller, R. R., \& Lewis, D. J. Retrograde amnesia produced by electroconvulsive shock after reactivation of a consolidated memory trace. Science, 1968, 160, 554-555.

Misanin, J. R., Vonheyn, R. E., Bartelt, S. W., Boulden, W. L., \& Hinderliter, C. F. The effect of hyperthermia on memory in rats. Physiological Psychology, 1979, 7, 339-344.

Mondadori, C., Waser, P. G., \& Huston, J. P. Time dependent effects of post-trial reinforcement, punishment, or ECS on passive avoidance learning. Physiology \& Behavior, 1977, 18, 1103-1109.

Newton, J. M., \& Wickens, D. D. Retroactive inhibition as a function of the temporal position of the interpolated learning. Journal of Experimental Psychology, 1956, 51, 149-154.

Quartermain, D., McEwen, B. S., \& Azmitia, E. C., Jr. Amnesia produced by electroconvulsive shock or cycloheximide: Conditions for recovery. Science, 1970, 169, 683-686.

Riвот, T. A. [The diseases of memory] (J. Fitzgerald, trans.). New York: Humboldt Library (No. 46), 1883.

Riccio, D. C., Hodges, L. A., \& Randall, P. K. Retrograde amnesia produced by hypothermia in rats. Journal of Comparative and Physiological Psychology, 1968, 66, 618-622.

Riccio, D. C., Mactutus, C. F., Hinderliter, C. F., \& McCutcheon, K. Severity of amnesia and the effectiveness of reactivation treatment: Evidence for a retrieval process. Physiological Psychology, 1979, 7, 59-63.

Riccio, D. C., \& Stikes, E. R. Persistent but modifiable retrograde amnesia produced by hypothermia. Physiology \& Behavior, $1969,4,649-652$

Richardson, R., Riccio, D. C., Jamis, M., Cabosky, J., \& 
Skoczen, T. Modification of reactivated memory through "counterconditioning." American Journal of Psychology, in press.

Robbins, M. J., \& MeYer, D. R. Motivational control of retrograde amnesia. Journal of Experimental Psychology, 1970, 84, 220-225.

Robertson, A. D., \& Inglis, J. The effects of electroconvulsive therapy on human learning and memory. Canadian Psychological Review, 1977, 18, 285-307.

Robustelli, F., Geller, A., \& Jarvik, M. E. Potentiation of the amnesic effect of ECS by detection. Psychonomic Science, $1968,12,85-86$.

Robustelli, F., Geller, A., \& Jarvik, M. E. Systematic analysis of the detention phenomenon in mice. Journal of Comparative and Physiological Psychology, 1972, 81, 472-482.

Rohrbaugh, M., \& Riccio, D. C. Paradoxical enhancement of learned fear. Journal of Abnormal Psychology, 1970, 5, 210-216.

Rozin, P. The psychobiological approach to human memory. In M. R. Rosenzweig \& E. L. Bennett (Eds.), Neural mechanisms of learning and memory. Cambridge: M.I.T. Press, 1976.

RUNQUiST, W. N. Interference among memory traces. Memory \& Cognition, 1975, 3, 143-159.

Russell, W. R. The traumatic amnesias. London: Oxford, 1971.

Schacte R, D. L., \& Crovitz, H. F. Memory function after closed head injury: A review of the quantitative research. Cortex, $1977,13,150-176$.

Schneider, A. M., \& Sherman, W. Amnesia: A function of the temporal relation of footshock to electroconvulsive shock. Science, 1968, 159, 219-221.

Schulenberg, C. J., Riccio, D. C., \& Stikes, E. R. Acquisition and retention of a passive avoidance response as a function of age in rats. Journal of Comparative and Physiological Psychology, 1971, 74, 75-83.

SIEGEL, S. Nonparametric statistics for the behavioral sciences. New York: McGraw-Hill, 1956.

Silve RSte in, A. Unlearning, spontaneous recovery, and the partial reinforcement effect in paired-associate learning. Journal of Experimental Psychology, 1967, 73, 15-21.

SPEAR, N. E. Forgetting as retrieval failure. In W. K. Honig \& P. H. R. James (Eds.), Animal memory. New York: Academic Press, 1971.

Spear, N. E. Retrieval of memory in animals. Psychological Review, 1973, 80, 163-194.

SPEAR, N. E. Retrieval of memories: A psychobiological approach.
In W. K. Estes (Ed.), Handbook of memory and cognitive processes (Vol. 4). Hillsdale, N.J: Erlbaum, 1976.

SPEAR, N. E. The processing of memories: Forgetting and retention. Hillsdale, N.J: Erlbaum, 1978.

Spear, N. E., Hamberg, J. M., \& Bryan, R. Forgetting of recently acquired or recently reactivated memories. Learning and Motivation, 1980, 11, 456-475.

Squire, L. R., Slate R, P. C., \& Chance, P. M. Reactivation of recent or remote memory before electroconvulsive therapy does not produce retrograde amnesia. Behavioral Biology, 1976, 18, 335-343.

Thompson, C. I., \& Grossman, L. B. Loss and recovery of long-term memory after ECS in rats: Evidence for state dependent recall. Journal of Comparative and Physiological Psychology, 1972, 78, 248-254.

Thompson, C. I., \& Neely, J. E. Dissociated learning in rats produced by electroconvulsive shock. Physiology \& Behavior, 1970, 5, 783-786.

Unde RWOOD, B. J. Attributes of memory. Psychological Review, 1969, 76, 559-573.

Wagner, A. R., Rudy, J. W., \& Whitlow, J. W., JR. Rehearsal in animal conditioning. Journal of Experimental Psychology Monograph, 1973, 97, 407-426.

WeAver, T. A., \& Geoffrey, M. Effect of unconditioned stimulus linked subconvulsive current in chicks. Psychonomic Science, $1969,5,265-266$.

WhitTy, C. W. M., \& Zangwill, O. L. (Eds.). Amnesia. London: Butterworth, 1966

WhitTy, C. W. M., \& Zangwill, O. L. (Eds.). Amnesia. London: Butterworth, 1977

Wickens, D. D., Tuber, D. S., Nield, A. F., \& Wickens, C. Memory for the conditioned response: The effects of potential interference introduced before and after original conditioning. Journal of Experimental Psychology: General, 1977, 106, 47-70.

WINER, B. J. Statistical principles in experimental design (2nd ed.). New York: McGraw-Hill, 1971.

Zinkin, S., \& Mille R, A. J. Recovery of memory after amnesia induced by electroconvulsive shock. Science, 1967, 155, 102-104.

Zubin, J., \& BARRERA, S. E. Effect of electric convulsive therapy on memory. Proceedings of the Society for Experimental Biology and Medicine, 1941, 48, 596-597.

(Manuscript received February 12, 1982; revision accepted for publication February 26, 1982.) 